\title{
Movimento e estagnação em Controle, de Natalia Borges Polesso
}

\author{
Movement and Stagnation in Controle by Natalia Borges Polesso \\ Movimiento y estancamiento en Controle de Natalia Borges Polesso
}

Júlia Braga Neves

\section{Resumo}

Este artigo tem o objetivo de analisar as relações entre movimento e estagnação nas construções dos espaços e da homossexualidade feminina no romance Controle, de Natalia Borges Polesso (2019a). Argumenta-se que a narrativa traça um paralelo entre a repressão da sexualidade não normativa da protagonista e sua condição médica marcada pela epilepsia e pela depressão, levando a personagem à reclusão na esfera doméstica. Embora esse paralelo possa incutir o risco de calcar a homossexualidade como patologia, a complexidade do enredo de Polesso mostra que a insegurança e o isolamento social da protagonista são superados pelo desejo homossexual, que é retratado como uma força que impulsiona o movimento da personagem. Por último, nota-se que o romance de Polesso retrabalha certos estereótipos presentes na literatura lésbica, como a exclusão social, o mito do amor trágico e o deslocamento como premissa para concretizar o encontro erótico, conforme apontam os estudos de Virgínia Maria Vasconcelos Leal.

Palavras-chave: espaço, literatura lésbica, Natalia Borges Polesso.

\begin{abstract}
This article aims to analyze the relations between movement and stagnation in the constructions of spaces and female homosexuality in the novel Controle (2019) by Natalia Borges Polesso. I argue that the narrative traces a parallel between the repression of the protagonist's non-normative sexuality and her medical condition marked by epilepsy and depression, which leads her to live under domestic confinement. Although this parallel may present the risk of coining homosexuality as a pathology, the story's complexity shows that the protagonist's insecurity and social isolation are overcome by homosexual desire, which is portrayed as a force that triggers movement in the character. Lastly, I discuss the ways that Polesso's novel reworks certain stereotypes that are present in lesbian literature, such as social exclusion, the myth of tragic love and displacement as a premise for the consolidation of erotic encounter, as it is shown by the studies developed by Virgínia Maria Vasconcelos Leal.
\end{abstract}

Keywords: space, lesbian literature, Natalia Borges Polesso.

\section{Resumen}

Este artículo tiene como objetivo analizar la relación entre movimiento y estancamiento en la construcción de espacios y la homosexualidad femenina en la novela Controle (2019) de Natalia Borges Polesso. Se argumenta que la narración establece un paralelismo entre la represión de la sexualidad no normativa por parte del protagonista y su condición médica marcada por la epilepsia y la depresión, lo que lleva al personaje a la reclusión en la esfera doméstica. Aunque este paralelo puede inculcar el riesgo de definir la homosexualidad como una patología, la complejidad de la trama de Polesso muestra que la inseguridad y el aislamiento social de la protagonista se ven superados por el deseo homosexual, que se representa como una fuerza que impulsa el movimiento del personaje. Finalmente, se observa que la novela de Polesso reformuló ciertos estereotipos presentes en la literatura lésbica, como la exclusión social, el mito del amor trágico y el desplazamiento como premisa para lograr el encuentro erótico, como lo señalan los estudios de Virgínia Maria Vasconcelos Leal.

Palabras-clave: espacio, literatura lésbica, Natalia Borges Polesso.

\footnotetext{
*Universidade de São Paulo (USP), São Paulo, SP, Brasil. (Dorcid.org/0000-0003-4548-3491. E-mail: juliabneves@gmail.com
} 
Vencedora do Prêmio Jabuti na categoria de contos e crônicas e da Escolha do Leitor com o seu livro Amora (2019a), Natalia Borges Polesso lançou em 2019 seu primeiro romance pela Companhia das Letras, protagonizado, como em seus contos, por mulheres lésbicas. Controle narra a trajetória de Maria Fernanda em busca de autonomia e liberdade, não somente sexual mas também da superproteção dos pais e do estado de depressão que a acompanha desde a adolescência. Nanda, como é chamada pelos amigos e pela família, é diagnosticada com epilepsia aos 14 anos de idade, o que muda completamente as suas relações familiares e perspectivas de socialização fora de casa. Com o diagnóstico, os pais passam a restringir cada vez mais a sua vida, e a personagem, por sua vez, começa a usar "chantagem como moeda de troca" (Polesso, 2019b, p. 54), ainda que os medicamentos tenham melhorado suas crises.

$\mathrm{O}$ "controle", que dá título ao livro de Polesso, refere-se a diversas formas de contenção que vão além da relação de Nanda com seus pais: o controle é tanto direcionado para aquilo que se pode (ou se tenta) moderar quanto para aquilo que não se consegue, de fato, controlar, como a epilepsia, a sexualidade e a depressão. Não se trata aqui de lançar mão dos discursos médicos para designar a homossexualidade como doença, como o fez a sexologia, a psicanálise e a psiquiatria no século XIX e na primeira metade do século XX (Foucault, 1990, p. 51-73; Green, 1999, p. 189-249; Cook, 2003, p. 73-94). No romance de Polesso, são a epilepsia e a depressão que caracterizam a estagnação que impede Nanda de experimentar e de se deslocar de seu ambiente familiar. Por outro lado, é a paixão contida de Maria Fernanda por Joana, sua melhor amiga e também lésbica, que permite que a protagonista compreenda a necessidade de dar um passo à frente no que diz respeito a sua vida e ao tratamento da epilepsia e da depressão. Dessa forma, em Controle, a realização de ser lésbica e de desejar outra mulher aparece como uma cura, um impulso para o início de uma vida aos 30 anos de idade.

Este artigo tem o objetivo de analisar as disposições de espaço no romance de Polesso, principalmente no que tange ao contraste entre movimento e estagnação da personagem. Enquanto o primeiro aspecto está relacionado às memórias da infância e da adolescência nas ruas de Campo Bom, no interior do Rio Grande do Sul, e à cura de Maria Fernanda da epilepsia, que a leva a São Paulo, onde vive Joana, a imobilidade da protagonista está calcada, sobretudo, na casa dos pais. A contraposição entre movimento e estagnação da personagem é crucial para a construção da homossexualidade de Nanda. Sua insegurança e seu isolamento provêm da forma pela qual as pessoas ao seu redor lidam com a epilepsia e como a doença afeta sua autoestima. Além de ter de enfrentar a superproteção dos pais, Maria Fernanda afasta-se de seus amigos com exceção de Joana, que persiste em se fazer presente, e Davi, que demonstra grande apreço pelas amizades de infância -, passando a ser conhecida na escola como "mina do tremelico".

O enredo é narrado em primeira pessoa pela própria protagonista, que conta sua história em retrospectiva, começando e terminando sua narrativa com o acidente de bicicleta em São Paulo, quando está a caminho da casa de Joana para lhe dizer que está apaixonada por ela. Ao relembrar suas memórias de adolescência, principalmente aquelas após o diagnóstico de epilepsia, e de juventude, Nanda relata tristeza e solidão como traços centrais desse período da vida. Ao passo que seus amigos terminam o ensino médio e ingressam na faculdade, Nanda não consegue terminar o supletivo, "não por causa da epilepsia, mas por uma série de acontecimentos catastróficos envolvendo a minha autoestima e uma falta de vontade de viver daquele jeito" (Polesso, 2019b, p. 64). Ela encontra um diário da época de escola, onde escreve "FUGA" (Polesso, 2019b, p. 65). Enquanto seus amigos aproveitavam a adolescência e Campo Bom se desenvolvia como cidade - com o terreno baldio onde se instalam uma "construção, depois o prédio de apartamentos novinho, e então o mesmo prédio um pouco desgastado pelo movimento da vida" -, enquanto o chão de terra de sua rua vira asfalto, Nanda está presa em sua própria solidão:

Eu fugi. Fugi daquilo tudo, da cena, das outras fotos e viagens que vieram. Mas foi porque eu não me sentia parte. Não tinha fotos de viagens, não tinha fotos de idas ao parque, às cascatas, às piscinas, às fazendas, ao estádio de futebol. [...] Não fui à excursão da oitava série, não tenho fotos das seguintes, em Florianópolis, Garopaba, Camboriú, na ilha do Mel. Não sei para onde foram. Meus pais ficaram com medo de me deixar ir, os 
professores também, meus colegas, que não eram meus amigos porque eu tinha perdido o ano, também não queriam a "mina do tremelico" estragando a viagem deles. Eu nem tinha mais tantas crises. [...] Isso ficou tão gravado no que sou, que até hoje sinto nojo de escola, das pessoas da escola. Digo "as pessoas da escola" e tremo (Polesso, 2019b, p. 65-66).

É a epilepsia que estigmatiza Maria Fernanda e que passa a defini-la como pessoa tanto para si mesma quanto para as pessoas ao seu redor. Apesar de tentar se desprender "dessas faltas", a protagonista diz ter ficado "com um monte de lacunas para completar" (Polesso, 2019b, p. 66) e não sabe como fazê-lo. Pode-se afirmar, portanto, que o próprio gesto de narrar sua história é uma maneira de tomar as rédeas das narrativas sobre si, preencher as lacunas, e criar uma versão cuja a autora é ela mesma. Essa estratégia é muito utilizada na literatura queer, conforme argumenta Eveline Kilian (2014) em seu artigo sobre a literatura como um espaço que possibilita diferentes possibilidades de ser para sujeitos intersexuais. Embora a protagonista de Polesso seja uma mulher-cis, é possível refletir sobre sua narrativa à luz das questões abordadas por Kilian.

Kilian compreende a literatura como uma heterotopia, 1 "um outro lugar, que, como argumenta Foucault, representa, questiona e subverte lugares reais" (Kilian, 2014, p. 40, tradução nossa). A literatura, que depende de seu caráter linguístico para existir, possibilita a reconfiguração de realidades por meio de representações de diversas conjunturas espaciais e temporais. É na literatura que Kilian percebe um potencial de transgressão da realidade vivida por sujeitos intersexuais, marcada pelo preconceito, pelos diagnósticos médicos e pelo estigma, pois a partir do aparato literário há a oportunidade de "se definir além dos limites das normas do mundo real e de estabelecer essas projeções narrativas do 'eu' numa relação dinâmica tocante à realidade vivenciada" (Kilian, 2014, p. 39-40, tradução nossa), podendo assim o sujeito queer se reposicionar dentro de discursos sociais e culturais que moldam sua experiência de vida como indivíduo não binário.

Ainda que o foco de seu artigo sejam narrativas literárias sobre sujeitos intersexuais, a autora comenta brevemente também os livros Why be happy when you could be normal? (2012) e Oranges are not the only fruit (1991), de Jeanette Winterson, renomada escritora inglesa cuja obra apresenta, em sua maioria, personagens lésbicas. ${ }^{2}$ Trata-se de ressaltar a relevância da literatura como espaço para representar o "eu". Por um lado, esse ato permite que o sujeito possa encarar a si mesmo por meio da distância criada entre o "eu" e sua representação. Por outro, a narrativa do "eu" proporciona "a possibilidade de dosar experiências dolorosas e transformá-las numa forma com a qual se possa lidar" (Kilian, 2014, p. 51, tradução nossa). Vale ressaltar que, até onde se sabe, não há referências à vida de Polesso em Controle, como acontece nos romances de Winterson. Porém, o incentivo de narrar o "eu" no romance é motivado justamente pelo fato de que Maria Fernanda sente que não consegue controlar sua vida, e a perspectiva de colocar a sua história numa narrativa ajuda a personagem a compreender sua paixão por Joana.

Essa questão é exteriorizada numa conversa com a amiga, na qual Nanda conta que irá se submeter à cirurgia para curar de vez a epilepsia. Joana demonstra preocupação em relação ao procedimento e a protagonista relata que sua decisão se deve ao fato de que os medicamentos, na verdade, "[temperam seu] cérebro pro cozido da epilepsia" e de que ela não tem "quase nenhum controle da [sua] vida". Nanda lamenta que sua "memória parece

\footnotetext{
${ }^{1}$ Kilian tem como base o conceito de heterotopia de Michel Foucault, que é discutido pelo autor em As palavras e as coisas: uma arquelogia das ciências humanas (1966) e no ensaio "Des espaces autres" (1984), publicado pela primeira vez na revista Architecture-Mouvement-Continuité e baseado numa palestra proferida em 1967 num congresso de arquitetura na França.

${ }^{2}$ Esses romances de Jeanette Winterson são particularmente importantes para o argumento de Kilian devido a seus aspectos temáticos e formais. Em seu romance de estreia, Oranges are not the only fruit, Winterson conta a história de uma jovem, Jeanette, que é adotada por um casal de evangélicos neopentecostais na Inglaterra. Na adolescência, a personagem descobre seu desejo por outras mulheres, o que desencadeia uma série de conflitos na esfera familiar, pois sua mãe adotiva busca uma cura para a filha por meio de exorcismos e outras práticas religiosas. Narrado em primeira pessoa, o romance é uma ficcionalização da vida da autora e é baseado nos mitos de origem da Bíblia, que são retrabalhados para a narração da jornada espiritual e psicológica da protagonista. Em 2012, Winterson lançou Why be happy when you could be normal?, que conta a mesma história de seu romance de estreia, mas sob o formato de autobiografia. Nesse livro, a autora explica que a narrativa de Oranges are not the only fruit foi a tentativa dela de controlar sua história e sua ficcionalização fora aquela que ela conseguia contar: "eu escrevi a história com a qual podia lidar. A outra era demasiadamente dolorosa. Eu não poderia sobreviver a ela" (Winterson, 2012, p. 6, tradução nossa). É na autobiografia que a relação conflituosa de Winterson com sua mãe adotiva, a busca por sua mãe biológica e a sua aceitação como mulher lésbica são confrontadas fora do âmbito ficcional e dentro de uma perspectiva da realidade.
} 
um labirinto fatiado", tendo sido altamente afetada por sua condição e seu tratamento e alegando que "queria que alguém reencenasse a [sua] vida para [ela] poder assistir" (Polesso, 2019b, p. 121-122). Joana sugere que Maria Fernanda escreva e a resposta é dada em seu texto e não pelo diálogo direto entre as personagens:

Joana, se tu soubesse que eu escrevo, sim, e muito, e que na maioria das vezes eu escrevo para fazer sair esse nó confusion in her eyes that says it all she's lost control feito de vontade e medo e de mais vontade e impossibilidade, se tu soubesse she gave away the secrets of her past and said I've lost control again se tu soubesse quantas vezes o meu descontrole foi despejado aqui no caderno com letra garranchada e rabiscada por cima, pra esconder, pra fingir que, dentro da minha apatia diária, tava tudo normal. Normal? O que é normalidade? and she turned around and took me by the hand and said I've lost control again eu não acredito que todos pensam que meu normal é isso que eu mostro por fora (Polesso, 2019b, p. 122).

Ao contrário da maioria das obras literárias que representa o amor entre mulheres, a suposta "anormalidade" de Maria Fernanda está projetada na epilepsia e na depressão e não em sua homossexualidade, que é relatada em seus diários, onde ela escreve sobre o amor por Joana, "sobre como mantínhamos essa amizade que era profundamente amorosa, e na mesma medida silenciosa, porque não dizíamos coisas importantes" (Polesso, 2019b, p. 123). A escrita é um espaço de fuga, uma maneira de expressar o descontrole e de reencenar sua vida para si. No trecho acima, nota-se um recurso utilizado por Polesso ao longo de todo o romance: a intertextualidade com letras de música.

Os fragmentos do excerto compõem a canção "She's lost control" (1979), do Joy Division, cujo vocalista, Ian Curtis, mencionado algumas vezes ao longo do romance, também tinha epilepsia e sofria de depressão, tendo se suicidado em 1980. Como a letra da música, a escrita de Maria Fernanda manifesta a importância de ter ao seu lado "ela" ("she"), que em seu caso seria Joana, para refletir sua própria inquietação e, sobretudo, dar-lhe a mão nos momentos de maior exasperação. A relação de Nanda com a música é narrada como uma maneira de ajudá-la a distrair do tédio e da estagnação física que dominam seu cotidiano, um ponto de fuga da realidade vivida pela protagonista. Como será visto na próxima seção, a reclusão e o isolamento de Nanda à esfera doméstica demonstram forte ligação com a construção de sua homossexualidade e de sua relação com a epilepsia e a depressão.

\section{0 doméstico}

Já em Amora (2019a), a esfera doméstica é um espaço que está presente em três contos como cenário principal: "Vó, a senhora é lésbica?", "Marília acorda" e "Minha prima está na cidade". Os dois primeiros retratam a homossexualidade feminina na terceira idade, em que as protagonistas estão à vontade com sua sexualidade e suas companheiras, embora seus relacionamentos não sejam assumidos para todos. Em "Vó, a senhora é lésbica?", vó Clarissa assume seu relacionamento com a tia Carolina para os netos no cotidiano da vida doméstica, fazendo com que sua neta mais velha, Joana, que também é lésbica, reflita sobre sua própria insegurança em assumir seu relacionamento com Taís para a família e os amigos. Em "Marília acorda", a domesticidade é apresentada pelo olhar da narradora sobre o processo de envelhecimento dela com sua companheira, Marília, dentro do conforto e da harmonia de seu lar, "atrás do muro que esconde o nosso pátio da rua e que esconde a nossa vida das pessoas" (Polesso, 2019a, p. 134). O espaço doméstico é visto como um acolhimento, um lugar onde o amor entre mulheres pode ser vivido sem medo e livre da homofobia das ruas.

Em "A minha prima está na cidade", é o embaraço do preconceito que adentra o domicílio de Bruna e de sua companheira, a narradora do conto que não consegue assumir sua homossexualidade. Pensando que a namorada estava em viagem, ela convida suas colegas de trabalho para jantar e, ao encontrar Bruna em casa quando chega acompanhada, a narradora fica constrangida e apresenta a parceira como sua prima que está na cidade para fazer o Enem. A dificuldade de assumir-se homossexual na esfera pública é a temática desse conto de Polesso, cujo ambiente central, o lar, funciona como o único recinto onde a narradora vivencia seu 
relacionamento, o qual ela só consegue expressar publicamente em lugares muito específicos e frequentados por outros homossexuais.

A relação entre o público e o privado é uma temática frequente das literaturas gay e lésbica, porque há a necessidade constante de negociar quando e onde se pode demonstrar gestos homoafetivos, como um simples beijo ou caminhar de mãos dadas. É verdade que a domesticidade tem uma conotação negativa quando se trata de literatura produzida por e que retrata mulheres, pois o lar aparece predominantemente como um espaço de confinamento aos papeis de maternidade e esposa. No entanto, remetendo-se à homossexualidade, a esfera doméstica pode adquirir diferentes significados, como acontece nos contos de Polesso citados aqui, onde a domesticidade é um conforto e um forte contra a homofobia do espaço público. Matt Cook afirma que o papel do lar é central para sujeitos homossexuais, cujas histórias são construídas tanto pelas "experiências nos lares onde nasceram quanto em suas partidas e/ou superação desses lugares para outros que possam preencher as funções simbólicas e práticas [do lar] de maneira mais ou menos queer" (Cook, 2012, p. 174, tradução nossa). Por um lado, o ambiente familiar pode ser tão ou mais homofóbico que a experiência homossexual das ruas e, muitas vezes, é o preconceito vivido dentro de casa que impulsiona a decisão de um sujeito queer deixar seu lar ou, nos piores casos, é a discriminação que determina a exclusão desse sujeito da família. Por outro, a vivência com outros indivíduos queer e o acolhimento possível por pessoas que já passaram por experiências semelhantes são fatores que permitem a construção de novos laços afetivos que podem estabelecer uma rede de apoio para aqueles que foram rechaçados por suas famílias.

No romance de Polesso, o ambiente doméstico não é definido pela homofobia, mas pelo demasiado controle exercido pelos pais sobre Maria Fernanda por conta de suas crises de epilepsia. Vendo o desgaste crescente de suas relações familiares, Nanda começa a se sentir "um fardo. Peso morto-vivo ou vivo-morto" (Polesso, 2019b, p. 45). Quando parentes perguntam sobre seus namorados, Nanda "já previa a cara da [sua] mãe se apressando em responder que primeiro [ela] devia [se] tratar e estudar e depois pensar em namorados. [...] Mas o que ela pensava é que [Nanda] jamais teria um namorado" (Polesso, 2019b, p. 49). Aos olhos dos familiares, a condição da protagonista automaticamente faz com que ela seja vista como um ser assexual, sem desejos. Dessa forma, a inibição da homossexualidade de Maria Fernanda pode ser relacionada a seu isolamento doméstico devido à epilepsia e, em contrapartida, pela maneira pela qual a personagem é vista como um ser cuja sexualidade é inexistente.

Isso fica mais claro quando a protagonista é contraposta à personagem de Joana, que conta à amiga que é lésbica quando elas têm a conversa sobre a cirurgia de Nanda. O diálogo é o primeiro no qual as duas personagens falam explicitamente sobre a intimidade de seus relacionamentos amorosos: Maria Fernanda não conta para Joana que tem um namorado virtual, o Antônio, e a amiga descobre isso pelo Davi, que é a pessoa que diz a Nanda que Joana está namorando. Ao ser confrontada sobre o porquê de não ter revelado esse namoro, Joana tenta fugir do assunto, alegando que, na verdade, não tinha muita vontade de namorar essa pessoa, cujo gênero, a princípio, não é explicitado. Pressionada por Nanda, Joana então admite que só está namorando esse rapaz por pressão dos pais, que "começaram a ir na igreja [...], eles nunca foram de ir na missa. Sabe a igreja que abriu naquele pavilhão abandonado onde era o antigo cinema?" (Polesso, 2019b, p. 124). Com o ingresso dos pais de Joana na igreja, muito provavelmente evangélica e neopentecostal, "umas coisas pesaram lá em casa", ela diz, e aproveita a oportunidade para se abrir, "Acho que sou gay, Nanda. [...] Acho, não. É isso. Sempre foi. Sempre vai ser. Já peguei" (Polesso, 2019b, p. 124). Joana tenta falar sobre as carícias trocadas entre elas, as vezes em que o relacionamento das duas parecera mais que uma amizade, mas Nanda impede que a conversa tome esse percurso.

$\mathrm{O}$ isolamento da protagonista em casa e a falta de experiências fora da esfera familiar são empecilhos para que ela possa aceitar e talvez até mesmo entender aquela "felicidade doída que nascia entre os pedregulhos da minha vontade" (Polesso, 2019b, p. 126), que Nanda sentira ao ouvir, pela primeira vez, que sua paixão por Joana pudesse ser correspondida ou até mesmo vivenciada. É em casa que a protagonista começa seu relacionamento virtual, que dura dos seus 
27 aos 30 anos, com Antônio, um rapaz carioca que também tem epilepsia e escreve um blog sobre o assunto. Ao contrário de Maria Fernanda, Antônio aparenta ter uma vida normal: ele surfa, tem amigos e vida social, e propõe ir até Campo Bom para visitar a namorada e conhecêla pessoalmente, o que Maria Fernanda recusa veementemente.

O capítulo que tem o relacionamento heterossexual da protagonista como foco é ironicamente intitulado "Irmandade", que define bem a relação de Nanda com Antônio. É ele quem incentiva Nanda a buscar novos tratamentos para a epilepsia e para a depressão; Antônio também aconselha Nanda a procurar um emprego e a voltar a estudar, a alcançar sua autonomia e independência. É o presente de aniversário de 30 anos que Nanda recebe de Antônio que concretiza a percepção de que ela precisava mudar o rumo de sua vida: "Não sabia que espécie bizarra de controle eu tinha sobre mim mesma que me fazia não viver, não experimentar. [...] Até ali, [...] aquele choro tinha sido recalcado até o último pedacinho de desejo de saída" (Polesso, 2019b, p. 102). O presente era um relógio de borracha verde que não mostrava as horas, mas apenas dizia "IT'S NEVER TOO LATE".

É no capítulo intitulado "Bizarro triângulo" que Nanda decide terminar com Antônio e que ela coloca em perspectiva sua paixão por Joana, sentindo "uma vergonha imensa de [si] mesma" (Polesso, 2019b, p. 104) por conta dos pensamentos sobre a amiga. O título do capítulo não é somente uma referência à famosa canção do New Order, "Bizarre Love Triangle" (1986), com o conhecido refrão "Everytime I see you falling/ I get down on my kees and pray/ Waiting for that final moment/ You say the words that I can't say", mas também é uma alusão ao triângulo amoroso entre Nanda, Antônio e Joana. Essas palavras que não podem ser pronunciadas são justamente aquelas que a protagonista deseja libertar, e Antônio, embora seja um bom amigo, tem a função de rechaçar a possibilidade de homossexualidade ou, na convivência familiar de Nanda, a assexualidade.

Como se sabe, a imagem do triângulo amoroso é frequente na literatura para afastar a possibilidade de homossexualidade. Segundo Eve Kosofsky Sedgwick, essa configuração é geralmente constituída por dois homens e uma mulher, na qual a mulher é representada como um objeto de troca cuja função é tornar evidente que as relações homossociais entre os homens não é de cunho homossexual (Sedgwick, 1985, p. 25-27; 2008, p. 27-36). Em Controle, esse triângulo é retratado por duas mulheres e um homem que, apesar de sua existência somente no plano virtual, atesta a heterossexualidade de Nanda e esconde qualquer possibilidade, ainda que remota, de que as pessoas percebam que ela é apaixonada por Joana.

Na visita de sua avó, sua tia e suas primas para seu aniversário de 30 anos, Nanda sente-se constrangida quando elas perguntam sobre esse namorado, chamado de "namoradinho da internet", e se já tinham se beijado ou se tocado: "uma obviedade brutal: nunca tínhamos nos tocado. Aliás, fora um selinho na sétima série eu nunca mais tinha me envolvido com ninguém" (Polesso, 2019b, p. 98). Durante essa conversa, Nanda tem uma crise de epilepsia brutal, como há tempos não tivera, porque havia substituído os medicamentos anticonvulsivos por tratamentos alternativos, recomendados por Antônio. Ao voltar para casa da consulta com seu médico e abrir o presente que ganhou de Antônio, o relógio com a mensagem, a protagonista se tranca em seu quarto, começa a pensar em tudo que deixou de viver e abre o armário para pegar o panfleto informativo que havia ganhado ainda na adolescência, quando teve sua primeira crise:

1. A EPILEPSIA NÃO É UMA DOENÇA MÁGICA, NEM SAGRADA, NEM, MUITO MENOS, DEMONÍACA. ELA É UMA DOENÇA NEUROLÓGICA COMUM. [...]

4. A EPILEPSIA NÃO PODE SER VISTA COMO UMA CATÁSTROFE. ELA É UMA CONDIÇÃO QUE TEM TRATAMENTO E QUE NA MAIOR PARTE DAS VEZES É BENIGNA.

5. A PESSOA COM EPILEPSIA É UMA PESSOA NORMAL. [...]

6. A EPILEPSIA POR SI SÓ NÃO GERA DESADAPTAÇ̃̃O SOCIAL. A SUPERPROTEÇÃO DOS PAIS EM RELAÇÃO À CRIANÇA PODE LEVAR A ALTERAÇÕES DE COMPORTAMENTO E PERSONALIDADE, TORNANDO A CRIANÇA, FREQUENTEMENTE, SOCIALMENTE ISOLADA, DEPENDENTE E INSEGURA (Polesso, 2019b, p. 47-48). 
O panfleto, no qual Nanda teria acreditado com tanta conviç̧ão durante toda a sua adolescência e juventude, era agora, aos 30 anos, posto em xeque, pois essas informações claramente não haviam sido seguidas por sua família nem por ela mesma. O papel ficava colado dentro do armário, agora "desbotado, semipregado na parte de dentro da porta" (Polesso, 2019b, p. 105). Num ataque de raiva, Maria Fernanda pega uma caneta atômica e começa a riscar o folheto: “A EPILEPSIA NÃO É UMA DOENÇA MÁGICA, NEM SAGRADA, NEM, MUTTO MENOS, DEMONÍACA."; ela causa desadaptação social, e a superproteção de seus pais desencadeiam "ALTERAÇÕES DE COMPORTAMENTO E PERSONALIDADE, TORNANDO A CRIANÇA, PESSOA, PORRA FREQUENTEMENTE, SOCIALMENTE ISOLADA, DEPENDENTE E INSEGURA" (Polesso, 2019b, p. 105). A substituição de "criança" por "pessoa" implica a própria presunção de que o indivíduo com epilepsia será infantil, principalmente quando se considera o fato de que, quando Nanda tivera sua primeira crise, ela tinha 14 anos e já não era mais uma criança. Ademais, é interessante notar que, em sua ira, a personagem risca também o fato de que as suas mudanças de comportamento a isolaram e a tornaram dependente. Seria esse gesto uma indicação de que seu isolamento social não é necessariamente uma consequência da epilepsia, mas talvez da depressão, repressão familiar e sexual?

Em sua narração desse momento, Maria Fernanda admite que "tinha acreditado tanto naquele papel, que [sua] vida tinha adquirido as dimensões dele. E pior, agora, trancada num armário. Finas ironias da vida" (Polesso, 2019b, p. 106). A crença naquele folheto, sugere-se, seria suficiente para criar uma falsa sensação de normalidade, a qual poderia ser contestada somente nos diários e cadernos de Nanda. Se o isolamento da protagonista pode ser atribuído à dificuldade de questionar os pais sobre seus cuidados excessivos, a realização de que estaria confinada ao armário - espaço que Sedgwick (2008, p. 72-75) identifica como um regime opressivo que depende da negociação entre o público e o privado, o segredo e a revelação, o explícito e o indizível - provoca o entendimento de que aquele era o momento de se rebelar. É aqui que Nanda rompe com Antônio e sai para andar pelas ruas da cidade, onde encontra Davi num boteco, com quem conversa, pela primeira vez, sobre sua vida íntima e amorosa.

Maria Fernanda está com medo de que sua paixão seja exposta, pois Antônio havia enviado uma mensagem a Joana para contar-lhe que Nanda terminara com ele: para ela, Antônio poderia estar desconfiado de que estivesse apaixonada por Joana e, por isso, teria escrito para ela. A protagonista não diz nada a Davi sobre sua paixão secreta, mas o amigo parece já saber que há algo a mais nessa relação, pois ele explica a Nanda que, de fato, ela fala muito sobre Joana e é mais do que natural que Antônio escreva para a amiga depois do término, pois ela é a pessoa mais próxima de Maria Fernanda. No dia seguinte, Nanda vê um cachorro machucado pela janela e sai de casa para ajudá-lo. A saída leva a uma caminhada, que a leva para uma loja onde compra um tênis para corrida. Há, nesse capítulo, no qual a protagonista passa a andar e correr nas ruas, uma sensação de leveza que culmina numa descrição de seu dia como "estranho" e "extraordinariamente simples" (Polesso, 2019b, p. 115). No entanto, ao lado da leveza de poder finalmente se aceitar, há também uma série de crises de convulsão, que levam Nanda novamente ao médico, o qual a aconselha a procurar um especialista em Porto Alegre para a realização da cirurgia.

A aceitação de seus desejos por Joana e seu término com Antônio amenizam o sentimento de isolamento de Nanda e, com isso, ela sente-se confiante em tomar a decisão de se submeter à cirurgia que cura a sua epilepsia. Dessa forma, pode-se afirmar que seu confinamento à vida doméstica é, em parte, associado à maneira pela qual ela lida com a própria homossexualidade. Nas palavras de Tânia Navarro-Swain, a solidão e o isolamento fazem parte de estereótipos propagados sobre o lesbianismo, frequentemente caracterizados pela "anormalidade, o desvio, a inversão, a exclusão" que figuram como "categorias em torno das quais transita ainda o medo de expressar sentimentos ou desejos voltados para o mesmo sexo" (Navarro-Swain, 2004, p. 40) Num primeiro momento, a sensação de anormalidade e de isolamento em Controle parece estar vinculado à epilepsia e à depressão da protagonista dentro do convívio familiar, pois a paixão por Joana é colocada em segundo plano e, de certa forma, suprimida como algo menos importante em sua vida. No entanto, quanto mais a personagem conversa sobre seus 
sentimentos e intimidade, mais claro fica que sua homossexualidade, atrelada ao isolamento doméstico e social, é um fator central de sua depressão e seu sentimento de anormalidade.

É interessante notar, por exemplo, que o psiquiatra de Maria Fernanda é quem fala "com todas as letras que [seu] maior problema não era a epilepsia" e, quando ela pergunta qual seria, então, seu problema, ele responde: "Tu sabe" (Polesso, 2019b, p. 90), Mais uma vez, implica-se o "indizível" e o parágrafo adiante retorna à Joana. A escolha de Polesso em relacionar a reclusão social da protagonista no limiar entre a epilepsia/depressão e a homossexualidade pode ser considerada problemática, pois se corre o risco de calcar a homossexualidade, como já foi feito ao longo da história, na patologia definida pelos discursos médicos. Contudo, esse risco é aplacado pela força que a paixão por Joana incute na protagonista e impulsiona seu movimento: o amor em Controle é o que dá o arranque ao movimento e à possibilidade de mudanças, como será discutido na próxima seção.

\section{Movimento}

Em artigo sobre as mulheres lésbicas na literatura contemporânea, Virgínia Leal identifica o deslocamento para outro espaço como uma tendência, o que ela caracteriza como "alteridade espacial" (Leal, 2008, p. 38), que permite que as relações amorosas entre mulheres sejam vivenciadas. Para Leal, "as personagens precisam estar fora de suas vidas cotidianas, em um deslocamento causado por uma viagem, uma doença (ou ambos), em um encontro com a morte ou com o sobrenatural, em desvios astronômicos, ou em quartos separados" (Leal, 2008, p. 44) para que o encontro homoerótico seja concretizado. No romance de Polesso, algumas dessas tendências são empregadas, como a viagem a São Paulo, a cura da epilepsia e o acidente de bicicleta em São Paulo (o "desvio astronômico") que impede que Nanda chegue até Joana.

As primeiras experiências sexuais de Nanda e Joana acontecem na casa desta, onde "ela [Joana] me abraçava e enroscava as pernas nas minhas", deixando Nanda "envergonhada [dela] mesma, de estar desejando coisas estranhas, desejando com o corpo" (Polesso, 2019b, p. 73). A relação erótica entre as duas ocorre depois que Nanda tem uma crise convulsiva na casa de Joana, que consegue acalmá-la e impedi-la de voltar para a casa dos pais. Elas conversam sobre como brincavam de lutinha na infância e a brincadeira, que se repete naquela ocasião quando ambas já estão em seus vinte e poucos anos, ganha conotação sexual e torna-se uma oportunidade de se tocarem. Deitadas na cama e escutando música juntas, elas começam a se acariciar até que, quando Joana toca em seus seios, Nanda fica com medo e diz que seu braço está dormente. As carícias cessam, mas Nanda continua sonhando:

A gente podia mesmo sonhar. Naquela noite, me permiti pensar sobre viagens loucas, sobre o lado selvagem da vida. Leveza profunda. [...] Cabia muita coisa se eu abrisse espaço, se deixasse a sanha de lado e o medo, quem sabe pudesse preencher o oco com outras sensações mais amenas, mais tenras. [...] Eu, com as duas mãos embaixo do travesseiro e, sobre ele, minha cabeça, que fervilhava de um jeito inconveniente e que até então eu não tinha permitido. Senti as pontas dos dedos formigar. Os espaços se inundando. Os braços de Joana desacelerando a noite. O mundo longe, preocupado com suas coisas de mundo. Nós na cama, guardadas. Eu só queria resolver um problema por vez. A epilepsia - problema número um - e o fato de eu ser completamente apaixonada pela Joana - problema número dois - desde sempre (Polesso, 2019b, p. 77).

Esse trecho evidencia a relação entre a epilepsia e a homossexualidade mencionada anteriormente, pois, além de a protagonista explicitar esse paralelo, as próprias reações físicas de excitação de Nanda, os dedos formigando, são atribuídas tanto às cenas eróticas quanto aos sintomas que precedem uma crise epiléptica. Numa de suas primeiras crises, ela também sente em seus dedos "formigas [caminhando] pelo [...] estofado do carro" (Polesso, 2019b, p. 38). Antes de sua crise na casa de Joana, Nanda sente uma "quentura no abdômen, um arrepio que travou com uma amarra na garganta" (Polesso, 2019b, p. 70-71), reações semelhantes àquelas sentidas enquanto escutam músicas e falam sobre como seria o beijo perfeito, quando a barriga de Nanda "ficou dura" e ela sente "os joelhos amolecerem e [...] a garganta seca" (Polesso, 2019b, p. 75). Os gestos sexuais só 
se tornam possíveis fora da casa de Nanda e, ainda que estejam em outro lar, este se apresenta como um local onde há abertura para deixar que seus desejos fluam, mesmo que temporariamente. Nesse momento, a protagonista consegue sentir a leveza que ela só sente novamente aos 30 anos, quando termina com Antônio e encara seus sentimentos por Joana. As lacunas e os vazios também são preenchidos provisoriamente com a aceitação de seus desejos "inconvenientes", mas confortantes e reais, e com a perspectiva de que eles seriam correspondidos.

Os episódios de movimento no romance estão associados a dois momentos distintos da vida de Maria Fernanda: o primeiro, em São Paulo, que ocorre na vida adulta, quando Nanda está a caminho da casa de Joana para declarar o seu amor; e o segundo, na adolescência, quando ela sofre um acidente de bicicleta que impulsiona sua primeira crise convulsiva. Este acidente ocorre na pista de bicicross que Nanda e seu amigo Alexandre constroem no terreno baldio em frente à sua casa, que seria palco para uma competição entre os dois. Antes de fazer sua volta, Nanda sente sua cabeça formigar, mas não liga, porque o importante seria superar o percurso quase perfeito realizado por Alexandre. A protagonista conclui o seu trajeto com perfeição, fazendo manobras e saltos perfeitos que deixavam "os vizinhos menores [...] boquiabertos" (Polesso, 2019b, p. 32), mas quando chega ao destino final, com a bicicleta muito acelerada, cai de cabeça no chão. A convulsão só ocorre depois de ter voltado do hospital e precisa voltar ao local, onde ela recebe o diagnóstico de epilepsia.

Enquanto o primeiro capítulo narra a infância de Nanda, o segundo capítulo relata a confusão mental da personagem logo que sofre o acidente de bicicleta em São Paulo e alguém lhe socorre na rua. Não sabemos, até esse ponto da narrativa, que a protagonista sofre de epilepsia, mas os capítulos subsequentes nos levam a pensar que esse acidente de bicicleta fora causado por uma crise convulsiva, tendo em vista que somos apresentados ao acidente de bicicross e aos desdobramentos de sua primeira crise convulsiva no capítulo seguinte. É somente no final do romance que conseguimos compreender por que a personagem estava em São Paulo: após seu longo percurso de amadurecimento, elucidados na seção anterior, Nanda volta a estudar, consegue terminar o ensino médio e inicia o cursinho para prestar o vestibular. Após a cirurgia, ela não tem mais crises convulsivas, embora ainda tome remédios para a depressão e ansiedade. Aos 34 anos, ela compra uma passagem para a capital paulista para ir a um show do New Order com Davi e Joana, que agora namorava Mari, e viaja sozinha pela primeira vez, escondida dos pais.

No aeroporto, Nanda conhece duas moças que também vão ao festival e, coincidentemente, ficarão hospedadas no mesmo bairro onde moram Joana e Mari. A sensação de liberdade de Maria Fernanda a deixa tão extasiada que ela tem o impulso de contar toda a sua vida para Bárbara e Flávia, que também são lésbicas. Queria dizer "que era virgem ainda e que [se] sentia uma retardada emocional" (Polesso, 2019b, p. 150) e que ela havia admitido para si mesma há pouco tempo que era lésbica. Isso não acontece no momento em que elas compartilham um táxi, mas depois, quando Nanda se perde de Joana e Davi logo que chega ao festival e encontra as duas moças no meio da multidão. Com elas, Maria Fernanda assiste ao show do New Order, toma ácido e fica com as duas ao mesmo tempo. Nanda não quer voltar para a casa de Joana e de Mari porque está com ciúmes e aceita o convite de Bárbara e Flávia para dormir no apartamento que alugaram para o final de semana.

É nesse lar provisório que a protagonista consegue relatar os detalhes de sua vida e, principalmente, falar sobre Joana. Ao escutar sua história, Bárbara e Flávia aconselham Nanda a ir atrás de Joana para se declarar, e é nesse percurso que Nanda sofre o acidente de bicicleta: o motivo dele não foi a epilepsia e, sim, a exaltação e a pressa, "Agora eu morro", ela repete, "Joana, quando eu te encontrar, eu vou tornar reais todas as vontades, todos os prazeres desconhecidos. Joana, vamos para Manchester? Vamos viver juntas?" (Polesso, 2019b, p. 171). Esses pensamentos sucedem no momento em que a protagonista está caindo, ela tem medo de morrer, embora sua vontade mesmo seja de viver: "Aposto que não morro nessa. Aposto que vivo mais. [...] Mas aposto que chego no chão antes que possam pensar em me segurar [...] Eu quero viver" (Polesso, 2019b, p. 171-172).

Os dois acidentes de Nanda, o da adolescência e o da vida adulta, são trágicas interrupções dos desejos da protagonista. Em Campo Bom, a queda de Maria Fernanda obstrui a 
possibilidade de uma vitória grandiosa numa competição acirrada com seu amigo, bem como impede a continuação de uma vida ativa e livre nas ruas da cidade, dando início a uma vida confinada e reclusa sob os cuidados parentais excessivos. Em São Paulo, o acidente susta o impulso de coragem de Nanda para dizer tudo que sente por Joana, impossibilitando também um final feliz para o relacionamento das duas personagens. Segundo Leal, a fatalidade ou a morte são temáticas recorrentes na literatura de Cíntia Moscovich, por exemplo, que "reelabora o mito do amor trágico e romântico, marcado pela fatalidade, em um viés homossexual que detona, finalmente, a sua expressão, até então sufocada" (Leal, 2008, p. 36). O acidente de Nanda é, por um lado, uma interrupção direta no possível desenvolvimento da amizade entre ela e Joana para um relacionamento amoroso. Por outro lado, é essa paixão que impulsiona o movimento de Nanda para perto dela e, consequentemente, contribui para sua própria libertação. Enquanto há, de fato, um sufocamento da manifestação desse amor, há também, pelo menos antes do acidente, uma porta de abertura para um futuro de autonomia e independência.

\section{Conclusão}

O primeiro romance de Polesso retrabalha alguns estereótipos já bastante disseminados na literatura lésbica, como demonstrei na seção anterior. Em artigo publicado em 2018, a autora de Controle aponta para algumas das temáticas recorrentes da literatura lésbica que também estão presentes em seu romance e em diversos contos de Amora, tais como "proibições, conflitos, desvios e términos de relações", além da reincidência de características específicas das personagens, que costumam ser jovens, de classe média ou alta e que dispõem de "determinado trânsito por grandes capitais (capitais ou cidades mais cosmopolitas)" (Polesso, 2018, p. 5). Em Amora, nota-se uma variação na faixa etária desse recorte, como nos contos "Marília acorda" e "Vó, você é lésbica?", e nas configurações espaciais de alguns contos que se passam no interior do Rio Grande do Sul, como "Flor, flores, ferro retorcido" e "Amora", por exemplo. Em Controle, essa cartografia verificada por Polesso é parcialmente subvertida, dado que o romance se passa predominantemente em Campo Bom e na esfera doméstica e que a circulação da protagonista na metrópole paulista é apenas passageira.

Quanto à construção das personagens, Polesso afasta-se de estereótipos que disseminam a imagem de que lésbicas sejam "dotadas de um furor sexual ou de uma frágil sexualidade, de uma pulsão sexual quase inexistente ou de um insidioso poder de sedução" (Navarro-Swain, 2004, p. 81). A percepção de que Maria Fernanda é desprovida de uma sexualidade é construída a partir da visão de seus familiares e de pessoas a seu redor pelo fato de ela ter epilepsia. Porém, ao tomar as rédeas de sua narrativa, Nanda busca compreender e afirmar seus desejos sexuais, escrevendo sobre seus próprios conflitos e experiências. Como se sabe, essa realidade ainda é muito presente entre jovens e adolescentes, que podem se sentir culpados e, como a protagonista, podem tentar reprimir os seus sentimentos homossexuais. Nesse sentido, as experiências de Maria Fernanda e de Joana como mulheres lésbicas contribuem para aumentar a visibilidade e fomentar a discussão sobre a homossexualidade feminina dentro dos campos literários e artísticos brasileiros, como mostram algumas pesquisas acadêmicas centralizadas nessa temática (Leal, 2008, p. 33-34; Polesso, 2018, p. 6-7; Leite e Oliveira, 2019, p. 101-103). No entanto, é necessário que, dentro da discussão sobre a representatividade lésbica na literatura e nas artes, haja também um questionamento sobre como estereótipos e chavões são reproduzidos nessas representações para que possamos, ainda que lentamente, criar novas matrizes discursivas para debater diferentes sexualidades.

\section{Referências}

COOK, Matt (2003). London and the culture of homosexuality, 1885-1914. Cambridge: Cambridge University Press.

COOK, Matt (2012). Queer domesticities. In: BRIGANTI, Chiara; MEZEI, Kathy (Org.). The domestic space reader. Toronto: University of Toronto Press. p. 173-179. 
FOUCAULT, Michel (1990). The history of sexuality: an introduction. Tradução de Robert Hurley. Nova York: Vintage. v. 1.

GREEN, James (1999). Além do carnaval: a homossexualidade masculina no Brasil do século XX. Tradução de Cristina Fino e Cássio Arantes Leite. São Paulo: Editora da Unesp.

KILIAN, Eveline (2014). Literarische Heterotopien: Ermöglichungsräume für Intergeschlechtliche Subjekte. In: BAIER, Angelika; HOCHREITER, Susanne (Org.). Inter*Geschlechtliche Körperlichkeiten: Diskurs/Begegnung im Erzahltext. Vienna: Zaglossos. p. 39-66.

LEAL, Virgínia Maria Vasconcelos (2008). Deslocar-se para recolocar-se: os amores entre mulheres nas recentes narrativas brasileiras de autoria feminina. Estudos de Literatura Brasileira Contemporânea, Brasília, n. 32, p. 31-45.

LEITE, Karoline Alves; OLIVEIRA, Rita Barbosa de (2019). Amor entre Amoras: a vivência lésbica nos contos de Natalia Borges Polesso. Trama, Marechal Cândido Rondon, v. 15, n. 34, p. 101-109.

NAVARRO-SWAIN, Tania (2004). O que élesbianismo? São Paulo: Brasiliense.

POLESSO, Natalia Borges (2019a). Amora. Porto Alegre; São Paulo: Não Editora.

POLESSO, Natalia Borges (2019b). Controle. São Paulo: Companhia das Letras.

POLESSO, Natalia Borges (2018). Geografias lésbicas: literatura e gênero. Criação E Crítica, São Paulo, n. 20, p. 3-19.

SEDGWICK, Eve Kosofsky (1985). Between men: English literature and male homosocial desire. Nova York: Columbia University Press.

SEDGWICK, Eve Kosofsky (2008). Epistemology of the closet. Berkeley; Los Angeles; Londres: University of California Press.

WINTERSON, Jeanette (1991). Oranges are not the only fruit. Londres: Vintage.

WINTERSON, Jeanette (2012). Why be happy when you could be normal? Londres: Jonathan Cape.

\section{Nota}

O presente trabalho foi realizado com apoio da Fundação de Amparo à Pesquisa do Estado de São Paulo (FAPESP), processo n ${ }^{\circ}$ 2019/16502-1. 